\title{
Surto de dictiocaulose em bovinos no município de Santa Maria, RS, Brasil
}

\author{
Outbreak of dictyocaulosis in cattle in Santa Maria, RS, Brazil
}

\section{Marcia Cristina da Silva ${ }^{1}$ Ricardo Rocha de Barros ${ }^{1}$ Dominguita Lühers Graça ${ }^{2}$}

RESUMO

Uma doença respiratória com morbidade de $7,1 \%$ e letalidade de $13,3 \%$ foi diagnosticada em terneiros de corte de 5 a 7 meses de idade na região central do Rio Grande do Sul, Brasil. Clinicamente, os bovinos apresentavam anorexia, perda de peso, tosse, taquipnéia, dispnéia, respiração abdominal e secreção nasal serosa. Lesões de necropsia observadas em dois terneiros incluíam acentuado edema pulmonar, enfisema e atelectasia pulmonares associados a nematódeos filiformes intra-bronquiais, com 8 a $10 \mathrm{~cm}$ de comprimento, morfologicamente compatíveis com Dictyocaulus viviparus. Histologicamente havia broncopneumonia fibrinosupurativa, peribronquite $e$ peribronquiolite linfo-histioplasmocitária, hiperplasia do epitélio brônquico, bronquiolite obliterante e hiperplasia de pneumócitos tipo II. No interior dos brônquios e bronquíolos, observaram-se muitos exemplares adultos de D. viviparus. Nos alvéolos, ovos e larvas cercados por numerosos eosinófilos e poucas células gigantes multinucleadas também foram encontrados.

Palavras-chave: doenças de bovinos, parasitas pulmonares, pneumonia verminótica, bronquite parasitária, dictiocaulose, Dictyocaulus viviparus, patologia.

\section{ABSTRACT}

A respiratory disease with morbidity and lethality rates respectively of $7.1 \%$ and $13.3 \%$ was diagnosed in $5-7$ month-old beef calves from the central region of Rio Grande do Sul, Brazil. Clinical signs included anorexia, loss of weight, cough, tachypnea, dyspnea, abdominal respiration, and serous nasal discharge. Gross lesions found in the necropsy of two affected calves included pulmonary changes such as edema, emphysema and atelectasis which were associated with 8-10cm long, filiform nematodes with morphology compatible with Dictyocaulus viviparus within the bronchi. Histologically there were fibrinosuppurative bronchopneumonia, lympho-histiocytic and plasmacytic peribronchitis and peribronchiolitis, bronchiolitis obliterans and type II pneumocyte hyperplasia. Within bronchi and bronchioli lumina there were numerous adult specimens of D. viviparus. Within alveoli there were numerous eggs and larvae of this nematode surrounded by large numbers of eosinophils and few multinucleated giant cells.

Key words: diseases of cattle, lung worms, verminous pneumonia, parasitic bronchitis, dictyocaulosis, Dictyocaulus viviparus, pathology.

\section{INTRODUÇÃO}

A verminose pulmonar de bovinos por Dictyocaulus viviparus (dictiocaulose) ocorre com maior freqüência em terneiros de raças leiteiras até um ano de idade, no verão ou outono, na primeira estação de pasto, ou em bovinos com exposição prévia mínima ou nula ao parasita (EYSKER, 1994; OGILVIE, 2000). Exemplares adultos de $\boldsymbol{D}$. viviparus são nematódeos finos $(0,2 \mathrm{~cm}$ de diâmetro) e alongados $(8-10 \mathrm{~cm}$ de comprimento) encontrados principalmente nos brônquios (URQUHART et al., 1990; DUNGWORTH,

\footnotetext{
${ }^{1}$ Médico Veterinário, aluno do Programa de Pós-graduação em Medicina Veterinária, área de concentração em Patologia Veterinária, Universidade Federal de Santa Maria (UFSM), 97105-900, Santa Maria, RS, Brasil. E-mail: mctogni@yahoo.com.br. Autor para correspondência.

${ }^{2}$ Médico Veterinário, PhD, Professor Titular do Departamento de Patologia, UFSM, Professor Orientador, Brasil. E-mail: dlgraca@smail.ufsm.br.
} 
1993; EYSKER, 1994; ZAJAC, 2002). Os ovos, que contêm larvas de primeiro estádio (L1), são expectorados, deglutidos e eclodem durante o trânsito pelo tubo digestivo. No solo, em condições favoráveis ao parasita, as larvas atingem o terceiro estádio (L3 estádio infectante) em uma semana (EYSKER, 1994; ZAJAC, 2002). Quando ingeridas, as L3 penetram na parede intestinal e circulam pelos vasos linfáticos e sangüíneos até os pulmões, onde cerca de uma semana pós-infecção (PI), atingem o quarto estádio (L4). A muda final para L5 ocorre após vários dias nos bronquíolos, e nos estádios subseqüentes os adultos jovens alcançam os brônquios (DUNGWORTH, 1993; EYSKER, 1994). Na dictiocaulose de bovinos, quatro fases podem ser distinguidas (EYSKER, 1994): 1) fase de penetração (desde que as larvas entram no hospedeiro até chegarem aos pulmões), 2) fase prépatente (desenvolvimento das larvas até adultos no pulmão), 3) fase patente (ovopostura pelos parasitas adultos no pulmão) e 4) fase pós-patente (com surgimento de sinais clínicos respiratórios graves nos estádios finais da doença). A cronologia de cada um dos estádios é respectivamente de 1-7 dias PI; 7-25 dias PI; 25-55 dias PI e 55-90 dias PI. A doença pulmonar é mais acentuada na fase pré-patente (BREEZE, 1985; ZAJAC et al., 2002).

A intensidade dos sinais clínicos depende de fatores como estádio da doença e carga parasitária, mas usualmente incluem anorexia, emagrecimento, tosse e taquipnéia. Febre ocorre quando há infecções bacterianas secundárias (OGILVIE, 2000; ZAJAC et al., 2002).

Embora seja uma condição comum em bovinos em regiões onde a parasitose é controlada, a conscientização sobre a doença pode decrescer tornando difícil a distinção entre esta e outras formas de doenças respiratórias em terneiros. O objetivo deste trabalho foi descrever a epidemiologia, os sinais clínicos e os achados patológicos de um surto de dictiocaulose em terneiros com a finalidade de contribuir com dados para facilitar o diagnóstico dessa condição respiratória.

\section{Surto da enfermidade}

Em maio de 2003, em Santa Maria, no Rio Grande do Sul, 15 terneiros de um lote de 210, cruza Nelore/Charolês de 5 a 7 meses de idade apresentaram anorexia, perda de peso, tosse, taquipnéia, dispnéia, respiração abdominal e secreção nasal serosa (Figura 1A). Alguns desses bovinos respiravam pela boca, com o pescoço estendido e os membros anteriores afastados. Dois animais morreram e na necropsia havia grande quantidade de espuma na porção final da traquéia e nos grandes brônquios; em meio a essa espuma eram observados numerosos parasitas brancoleitosos e filiformes com 8 a $10 \mathrm{~cm}$ de comprimento identificados como Dictyocaulus viviparus (Figura 1C). O pulmão estava vermelho, firme e pesado, principalmente nos lobos caudais, com áreas multifocais brancas elevadas (enfisema) e outras vermelhas deprimidas (atelectasia), conferindo padrão moteado ao órgão (Figura 1B). Na superfície de corte, havia numerosos pontos acinzentados de $1 \mathrm{~mm}$ de diâmetro (Figura 1D) distribuídos aleatoriamente pelo parênquima e alguns exemplares de $\boldsymbol{D}$. viviparus na luz dos brônquios. Fragmentos de pulmão foram fixados em formol a $10 \%$ e processados rotineiramente para histopatologia. Microscopicamente, o epitélio brônquico estava moderadamente hiperplásico e havia hiperplasia dos acúmulos linfóides peri-brônquicos (BALT). Grande quantidade de $\boldsymbol{D}$. viviparus adultos era observada no interior dos brônquios (Figura 1E); na luz dos bronquíolos havia extenso infiltrado inflamatório formado por eosinófilos, por vezes circundando larvas de nematódeos. Em alguns casos, o infiltrado eosinofílico obstruía totalmente a luz dos bronquíolos. Bronquiolite obliterante foi um achado freqüente. No interior dos alvéolos havia grande quantidade de material róseo e homogêneo (edema), fibrina, neutrófilos íntegros e degenerados, eosinófilos e macrófagos espumosos. A maioria dos alvéolos era revestida por uma dupla camada de células epiteliais (proliferação de pneumócitos tipo II). No interior dos alvéolos, evidenciaram-se ovos e larvas circundados por grande quantidade de eosinófilos e poucas células gigantes multinucleadas.

\section{DISCUSSÃO E CONCLUSÕES}

O diagnóstico de dictiocaulose foi baseado nos sinais clínicos, dados epidemiológicos (época do ano, idade dos animais) e nos achados de necropsia e histopatologia que foram semelhantes aos descritos para essa condição (BREEZE, 1985; DUNGWORTH, 1993; OGILVIE, 2000; ZAJAK et al., 2002).

A doença observada nos dois bezerros necropsiados deste caso pode ser classificada como na fase patente. Nessa fase, os sinais clínicos são associados a lesões de broncopneumonia primária produzida pelos parasitas adultos nos brônquios. É comum se observar macrófagos no exsudato e células gigantes fagocitando ovos e larvas (EYSKER, 1994). A doença começa na fase pré-patente, quando os bronquíolos e pequenos brônquios são obstruídos por exsudato e os alvéolos colapsam devido à obstrução (LÓPEZ, 1998). Áreas de atelectasia foram

Ciência Rural, v.35, n.3, mai-jun, 2005. 


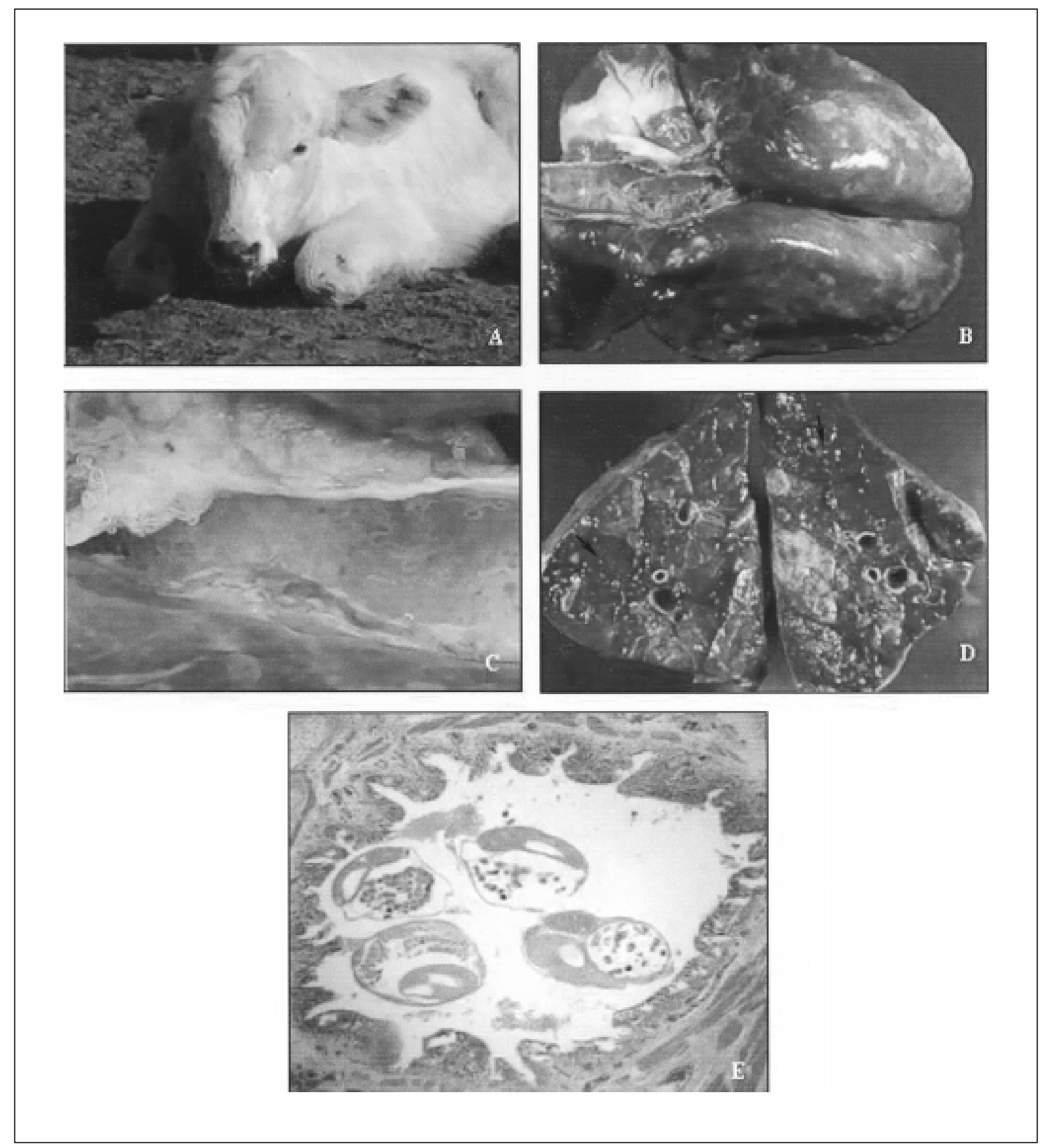

Figura 1 - A. Bovino; 5 meses. Secreção nasal serosa e apatia. B. Traquéia e pulmão; bovino. Observam-se numerosos parasitas adultos de Dictyocaulus viviparus no interior da traquéia. No pulmão, há áreas de enfisema e atelectasia. C. Traquéia; bovino. Visão aproximada da Figura 1B. D. Pulmão; bovino. Presença de pontos acinzentados de 1mm de diâmetro (setas) distribuídos aleatoriamente no parênquima. E. Pulmão; bovino. Aspecto microscópico. No interior dos brônquios, há cortes tranversais de parasitas adultos de $\boldsymbol{D}$. viviparus.

observadas no pulmão dos terneiros deste surto. Em geral, na fase pós-patente, os bovinos gradualmente se recuperam (ZAJAC, 2002); no entanto, em cerca de $25 \%$ dos animais afetados uma exacerbação dos sinais clínicos pode ocorrer (EYSKER, 1994).
Clinicamente, os diagnósticos diferenciais devem incluir as pneumonias pelos vírus sincicial respiratório bovino e da parainfluenza-3, as pneumonias bacterianas, e as pneumonias intersticiais tóxicas e alérgicas. Detalhes sobre o

Ciência Rural, v.35, n.3, mai-jun, 2005. 
diagnóstico diferencial de todas essas condições podem ser encontrados em uma revisão publicada pelo Setor de Patologia Veterinária da UFSM (FIGHERA et al., 2003). Em condições graves como deste relato, há mortes e a necropsia é conclusiva para o diagnóstico.

Em casos clínicos, o diagnóstico pode ser confirmado pela determinação do número de larvas por grama (LPG) de fezes pelo método de Baermann, em que quantidades superiores a 50 LPG de fezes caracterizam uma infestação grave (RUAS, 2001).

\section{REFERÊNCIAS BIBLIOGRÁFICAS}

BREEZE, R. Parasitic bronchitis and pneumonia. Veterinary Clinics of North America: Food Animal Pratice, v.1, p.277-287, 1985.

DUNGWORTH, D.V.F. The respiratory system. In: JUBB, K.V.F.; et al, Pathology of domestic animals. 4.ed. San Diego : Academic, 1993. p.539-699.
EYSKER, M. Dictyocaulosis in cattle. Compendium on Continuing Education for the Practicing Veterinarian, v.16, p.669-672, 1994.

FIGHERA, R.A. et al. Pneumonia intersticial em bovinos associada à ingestão de batata-doce (Ipomoea batatas) mofada. Pesquisa Veterinária Brasileira, v.23, p.161-166, 2003.

LÓPEZ, A. Sistema respiratório. In: CARLTON, W.W.; McGAVIN, M.D. Patologia veterinária especial de Thomson. Porto Alegre : ArtMed, 1998. p.132-193.

OGILVIE, T.H. Medicina interna de grandes animais. Porto Alegre : Artes Médicas Sul, 2000. 568p.

RUAS, J.L. Doenças parasitárias. In: RIET-CORREA, F. et al. Doenças de ruminantes e eqüinos. 2. ed. São Paulo : Varela, 2001. p.85-89.

URQUHART, G.M. et al. Parasitologia veterinária. Rio de Janeiro : Guanabara Koogan, 1990. 306p.

ZAJAC, A.M. Parasitic bronchitis and pneumonia. In: SMITH, B.P. Large animal internal medicine: diseases of horses, cattle, sheep, and goats. 3.ed. Missouri : Mosby, 2002. p.577-579. 